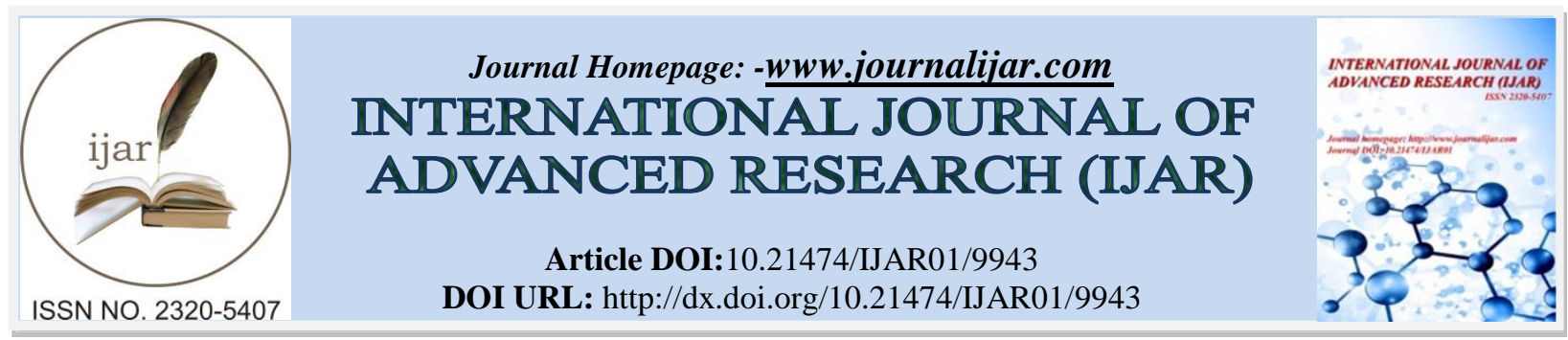

RESEARCH ARTICLE

\title{
KNOWLEDGE, ATTITUDE, AWARENESS ON RATIONAL USE OF DRUGS AMONG THE PARA- MEDICAL STUDENTS IN A TERTIARY CARE HOSPITAL - A QUESTIONNAIRE BASED STUDY.
}

Shafaiyaz.M ${ }^{\mathbf{1}}$ and Yamuna devi M.S ${ }^{\mathbf{2}}$.

1. II year MBBS, Saveetha Medical College, Thandalam, Chennai-602105, India.

2. Assistant Professor, Department of Pharmacology, Saveetha Medical College, Thandalam, Chennai.

\section{Manuscript Info}

Manuscript History

Received: 18 August 2019

Final Accepted: 20 September 2019

Published: October 2019

Key words:-

Rational use of medicines, Questionnaire, Knowledge, Awareness, Attitude.

\section{Abstract}

Introduction:Drugs are prescribed on the basis of the severity of the medical condition with which the patient is seeking the hospital. But irrational use of drugs has put the healthcare of the patients at risk. Irrational usage may be due to their false beliefs and limited knowledge about the drugs.

Aim \&objective:The present study was aimed to assess the knowledge, attitude, and awareness about the rational use of drugs among Paramedical students in tertiary care hospital.

Methodology:This cross-sectional questionnaire based study was conducted in Saveetha Medical College and Hospital, Chennai between January 2019 and May 2019. A total of 250 para-medical students of were included. A pretested semi-structured questionnaire with about 35 questions was used to assess the participants. A descriptive analysis of the data was done using SPSS software version 20.

Results:Only 38\% participants felt safe of having self medication and about $47 \%$ participants were aware about the Over the Counter (OTC) medicines. But surprisingly, $86 \%$ participants agreed that they will purchase all medicines written in the prescription and $79 \%$ participants strongly agree and stick to doctor's advice and instructions. The knowledge and awareness towards the usage of drugs rationally was encouraging and the attitude towards it was also promising as about 96\% participants have the knowledge of taking the precautions while using the medicines and only $38 \%$ participants agreed to the attitude that costlier medicines are better than cheaper ones.

Copy Right, IJAR, 2019,. All rights reserved.

\section{Introduction:-}

Since time immemorial diseases have plagued the human existence and has led to the loss of precious human lives. But various scientific innovations and better understanding of diseases has enabled the discovery of cure for various such diseases. Drugs are important factors which alleviate the diseases thereby promoting human well being. Information obtained from medication knowledge assessment could aid in developing an appropriate healthcare improvement plan (1). But nowadays the drugs are being exploited and are being used irrationally.

According to a report by World Health Organization (WHO), 50\% of all medicines are prescribed, dispensed or sold incorrectly, while $50 \%$ of patients fail to take their medicines satisfactorily (2). Health care officials have become 
completely oblivious to the old and evergreen techniques of diagnosis and are more dependent on the drugs to do their work. The patients also play an equally important pivotal role as their reliance on over the counter [OTC] medications for simple trivial conditions have also irrationally exploited the drug use.

Irrational usage may be due to the false beliefs and limited knowledge about the drugs. As a result, the drugs which were precious in saving human lives by ameliorating the disease are now rendered useless by acquiring resistance. This in turn has resulted in patient morbidity and mortality being gradually increasing due to lack of medical adherence and polypharmacy leading to treatment failure and death. To know the extent of irrational use of drugs, we must know the awareness among the young population. Hence the aim of this study was to assess the knowledge, attitude, and awareness about the rational use of drugs among Para-medical students in tertiary care hospital.

\section{Methodology:- \\ Study Setting:}

This Cross- sectional questionnaire based study was conducted in Saveetha Medical College and Hospital, Chennai with the aim to assess the knowledge, attitude and awareness on rational use of drugs among the Para-medical students between January 2019 and May 2019.

\section{Ethics Approval:}

Approval from the Institutional Review Board, Saveetha Medical College and Hospital was obtained prior to the initiation of study (SMC/IEC/2018/11/498).

\section{Study Participants:}

The Para-medical students falling between the age group from 17 to 23 , both males and females were included in this study and a written informed consent was obtained from all the participants. There were no particular exclusion criteria.

\section{Study Method:}

A pretested Semi-structured questionnaire was used to assess the study participants. The questionnaire consisted of about 35 questions in 3 parts - 12 questions on Knowledge, 12 questions on Awareness and remaining 11 questions on Attitude. A descriptive analysis of the data was done using SPSS software version 20 and results interpreted.

\section{Results:-}

The study was performed in a sample of 250 para-medical students. There was a preponderance of female participants of about $74 \%$ where as the males were just $26 \%$. Majority of the participants were from urban area and have studied in private schools. (Table.1)

When questioned about the awareness about over the counter (OTC) medicines to the 250 para-medical students, $47 \%$ participants were aware while remaining 53\% participants were not aware about the OTC can be safety taken with prescription medicines while $26 \%$ participants disagreed and $36 \%$ participants were not aware. $58 \%$ participants were aware about generic medicine and the remaining $42 \%$ participants were not aware. When asked about a question that the same generic content of medicines is available under different names $66 \%$ participants agreed $15 \%$ participants disagreed while $19 \%$ participants were not aware.(figure.1)

About 96\% participants have the knowledge of taking the precautions which using medicine in pregnant and breastfeeding women whiles the remaining $4 \%$ participants are unaware. When questioned about the awareness about over-the counter (OTC) medicines to the 250 para-medical students, $47 \%$ participant were aware while remaining 53\% participant were not aware about the OTC medicine $38 \%$ participant agree that OTC can be safety taken with prescription medicines while $26 \%$ participants disagreed and $36 \%$ participants were not aware $58 \%$ participant were aware about generic medicines and the remaining $42 \%$ participant were not aware. When asked about a question that the same generic content of medicine is available under different names, $66 \%$ participants agreed to that question and 15\% participants disagreed while 19\% participants were not aware. About $96 \%$ participants have the knowledge of taking the precautions while using medicines in pregnant and breast feeding women while the remaining $4 \%$ participants are unaware. 
The participants were then questioned on their attitude towards drugs as the costlier medicines are better than cheaper ones for which $38 \%$ of the students agreed, $39 \%$ disagreed and the remaining $23 \%$ were not aware about the correlation between cost and the quality of drugs. $33 \%$ of total participants had an attitude that medicines manufactured by foreign multinational companies are better. But when asked about the fact that is it important for patient to know about common side effects of medicines, $73 \%$ of the participants strongly agreed and $27 \%$ of the participants disagreed. Whe asked whether mass communication is a bad medium to educate about medicines for which $30 \%$ participants agreed and remaining $70 \%$ participants strongly disagreed. (figure.2)

250 participants were asked a question assessing their approach towards drug. Majority of them agreed to the fact that they will take medicines only after reading the label on it. Brand name and the expiry date were the main categories of choice. Other categories are listed below (figure.3).

Around $30 \%$ participants preferred that antibiotics should be available without doctor's prescription but the remaining $70 \%$ participants strongly were against this attitude. $51 \%$ participants had an attitude that antibiotics can be stopped if the symptoms disappear and the remaining 49\% participants were against this attitude. About $48 \%$ participants agreed to the fact that medicines can be bought without prescription where as the around $52 \%$ participants strongly disagreed. (figure.4)

Re-usage of the prescription for similar complaints in other person is not advisable as the diagnostic conditions may differ and for which around 64\% participants were aware and strongly disagreed. Around $86 \%$ participants agreed that they will purchase all medicines written in the prescription and $79 \%$ participants strongly agree and stick to doctor's advice and instructions where as remaining participants were not having a basic knowledge of following doctor's advice \& instructions. Out of 250, 76\% participants consult the doctor before stopping any medicine but remaining $24 \%$ participants was not aware about its importance.

\section{Discussion:-}

This study takes into consideration the existing knowledge and attitude, of the Para medical students about various issues concerned about rational usage of drugs. Assessing the knowledge, attitude and awareness among the young growing population is an important step in the process of creating awareness in the society on rational drug usage. Hence assessing the knowledge of para medical students who are a part of the healthcare team would be helpful in promoting the rational use of drugs and improving the awareness of the society.

It is well known that safe and effective drug therapy is possible when patients are well informed about medications and about their use and side effects if taken without prescription (1). In the present study majority of the participants had the knowledge and were aware about most of the issues concerned with the rational usage of drugs as addressed in the questionnaire which seems to be a promising finding but in a long run it is a must for all of them to have appropriate knowledge about all the issues addressed (2). Surprisingly only $47 \%$ of the participants were aware about over the counter (OTC) medicine. Ironically only $38 \%$ felt that OTC can be safely taken with the prescription medicines. Though the knowledge about such issues is a part of the practical curriculum of the students, the unawareness may be because majority of the participants were belonging to the first and second years of the respective para medical courses that have not yet completed their practical training. The basic idea of personal drug for the undergraduate practical curriculum is a good motive to promote rational use of safe and suitable drugs. However, this concept needs to be utilized in its right perspective so that it does not leave enough to question its utility $(3,4)$.

Another study reported that most of the patients were not aware of the name, composition and side effects of the drugs prescribed to them. $(5,6)$ But in this study majority of the participants had the attitude of reading the label on the medicines before using it but only $14 \%$ of them look for its brand name and $16 \%$ look for its expiry date. Ironically only $6 \%$ among them look fee the generic name of the drug. These findings are similar to the previous study conducted by smita.et al. (7-8) This is not an encouraging finding and needs to be corrected because using or prescribing medicines by generic names is an important measure in the rational use of drugs. A bunch of previous studies show that high incidence of drug prescribing errors and irrational usage of drugs is mainly due to inadequate pharmacology teaching (9-12). In spite of numerous methods which were developed by healthcare institutions for an improvement in the rational usage like mandatory prescription note needed for any drug to be purchased, excessive and inappropriate antibiotic prescribing is still a major problem which is prevalent throughout the world (13). In 
order to overcome this situation, all the students who are undergraduates should be taught about the rationale of usage of drugs.

But surprisingly majority of the participants around $79 \%$ do stick to the doctor's advice and instruction regarding the prescribed drugs and $87 \%$ of the participants strongly disagree with the concept of mixing allopathic treatment with either of ayurvedic traditional home remedy homeopathy or unani. This gives a positive result on this study that majority of students possess good attitude and awareness and their knowledge about rational use of drugs were encouraging under the same time has to be improved.

\section{Conclusion:-}

The knowledge and awareness towards the usage of drugs rationally was encouraging and the attitude towards it was also promising as about $96 \%$ participants have the knowledge of taking the precautions while using the medicines and only 38\% participants agreed to the attitude that costlier medicines are better than cheaper ones. Although irrational use of drugs is an important issue, but teaching about rational usage of drugs is not given much importance in most of the medical colleges. Considering the future of these students, they should be made aware of all the aspects of rational use of drugs and improper knowledge regarding certain aspects which in turn is a matter of concern needs to be addressed.

Table 1:-Demographic details of the Para- medical students.

\begin{tabular}{|c|c|c|c|}
\hline S.NO & PARAMETERS & & CENTAGE \\
\hline 1. & Age & $\begin{array}{ll}\text { - } & <20 \text { years } \\
\text { - } & >20 \text { years }\end{array}$ & $\begin{array}{l}92 \% \\
8 \%\end{array}$ \\
\hline 2. & Sex & $\begin{array}{ll}\text { - } & \text { Male } \\
\text { - } & \text { Female }\end{array}$ & $\begin{array}{l}26 \% \\
74 \%\end{array}$ \\
\hline 3. & Course & $\begin{array}{ll}\text { - } & \text { Ahs } \\
\text { - } & \text { Bot } \\
\text { - } & \text { Bpt } \\
\end{array}$ & $\begin{array}{l}26 \% \\
42 \% \\
32 \%\end{array}$ \\
\hline 4. & Place of origin & $\begin{array}{ll} & \text { Rural } \\
\text { - } & \text { Urban }\end{array}$ & $\begin{array}{c}4 \% \\
96 \%\end{array}$ \\
\hline 5. & Year of study & $\begin{array}{ll}\text { - } & \text { I year } \\
\text { - } & \text { II year } \\
\text { - } & \text { III year }\end{array}$ & $\begin{array}{l}46 \% \\
21 \% \\
33 \%\end{array}$ \\
\hline 6. & School & $\begin{array}{ll}\text { - } & \text { Government } \\
\text { - } & \text { Private }\end{array}$ & $\begin{array}{c}8 \% \\
92 \% \\
\end{array}$ \\
\hline 7. & Board of study & $\begin{array}{ll}- & \text { State board } \\
\text { - } & \text { CBSE }\end{array}$ & $\begin{array}{c}95 \% \\
5 \%\end{array}$ \\
\hline
\end{tabular}


Figure 1:-Evaluation of the participant's knowledge regarding rational use of drugs

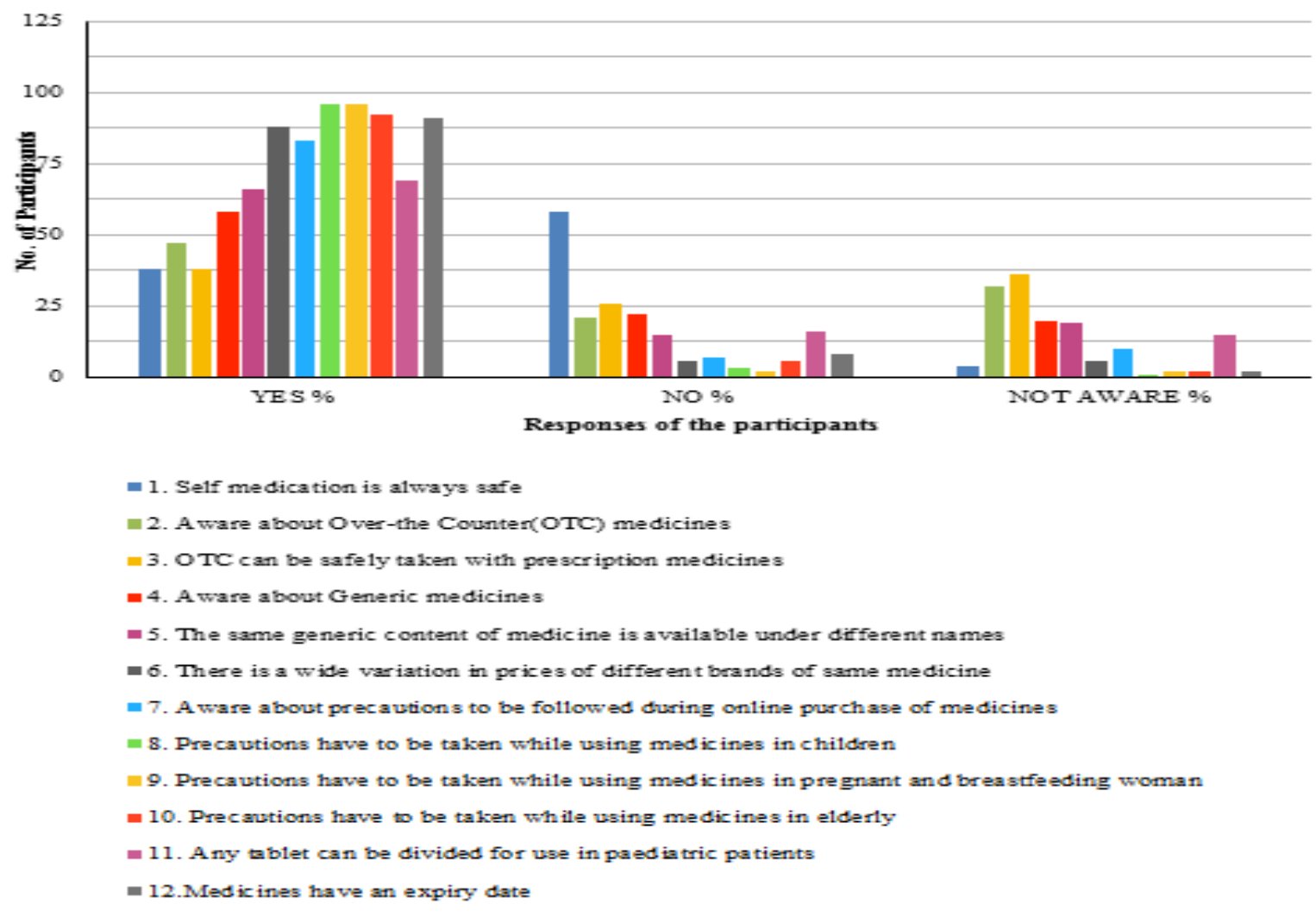

Figure 2:- Evaluation of the participant's attitude towards the rational use of drugs

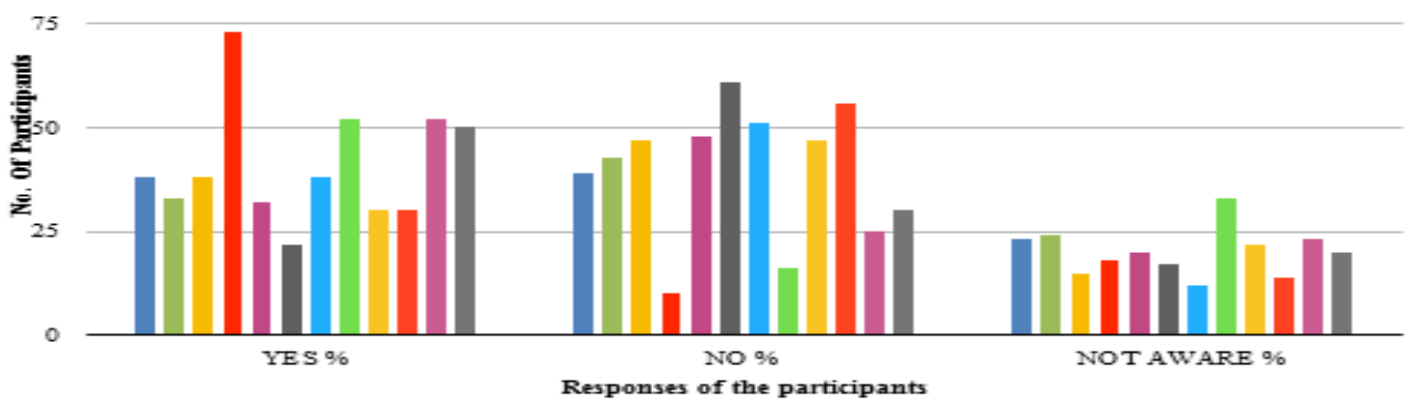

=13. Costlier medicines are better than cheaper ones

=14. Medicines manufactured by fore ign multina tional companies are better

w15. Medicine is needed for every illness Legend

=16. Its important for patient to know common side effects of medic ines

=17. More the number of medicines in a preacription better and earlier will be the relief

=18. Medicines from govemment hospitals are of inferior quality as compared to those from private pharmacies

=19. Doctors can completely depend on information about medicines provided by phama industries

$=20$. Gain by irational prescribing is maximum to phama industries

$=21$. Mass communication is a bad medium to educate people about medicines

$=22$. Antibiotics should be available without doctors prescription

=23. If antibiotics are used frequen dy, Bacteria may not respond to the antibiotic in the future

=24. Antibiotics can be stopped if the symptoms disappear 
2. Divya Sree $\mathbf{P}$ et al. Evaluation of knowledge, attitude and practice towards drug use along with good pharmacy practice among pharmacy students of Sri Venkateswara College, Chittoor, India. Int. Res. J. Pharm. 2017;8(3):29-32

3. Parmar DM, Jadav SP. The concept of personal drugs in the undergraduate pharmacology practical curriculum. Indian Journal of Pharmacology. 2007 May 1;39(3):165.

4. Khilnani G. The concept of personal drugs in the undergraduate pharmacology practical curriculum. Indian journal of pharmacology. 2008 May 1;40(3):131-2.

5. Bajait CS, Pimpalkhute SA, Sontakke SD, Dakhale GN, Jaiswal KM, Urade CS. Evaluation of knowledge, attitude and practice of rational use of medicines among clinicians in a tertiary care teaching hospital. International Journal of Nutrition, Pharmacology, Neurological Diseases. 2014 Jul 1;4(3):153.

6. Basaran NF, Akici A. Patients' experience and perspectives on the rational use of drugs in Turkey: a survey study. Patient preference and adherence. 2012;6:719.

7. Sontakke SD, Budania RJ, Paranjape SG. Evaluation of knowledge, attitude and behavior about rational use of medicines in second year medical students. IJBCP. 2013;2(5):617-21.

8. Mahajan R, Singh NR, Singh J, Dixit A, Jain A, Gupta A. Current scenario of attitude and knowledge of physicians about rational prescription: A novel cross-sectional study. Journal of Pharmacy and Bioallied Sciences. 2010 Apr;2(2):132.

9. Hooli TV, Srikanth, Somashekara SC, Suraj B. Knowledge, attitude, practice of rational use of medicines among junior residents in a tertiary care hospital. Int J Basic Clin Pharmacol 2017;6:2001-4.

10. Gwee MC. Teaching of medical pharmacology: the need to nurture the early development of desired attitudes for safe and rational drug prescribing. Medical teacher. 2009 Jan 1;31(9):847-54.

11. Oshikoya KA, Senbanjo IO, Amole OO. Interns knowledge ofclinical pharmacology and therapeutics after undergraduate and ongoinginternship training in Nigeria: a pilot study. BMC Medical Education. 2009;9(1):50.

12. Rothwell C, Burford B, Morrison J, Morrow G, Allen M, Davies C, et al. Junior doctors prescribing: enhancing their learning in practice. Br J Clin Pharmacol. 2011;73(2):194-202.

13. Remesh A, Gayathri AM, Singh R, Retnavally KG. The knowledge, attitude and the perception of prescribers on the rational use of antibiotics and the need for an antibiotic policy-a cross sectional survey in a tertiary care hospital. Journal of clinical and diagnostic research: JCDR. 2013 Apr;7(4):675. 